\title{
DEZ ANOS DA REVISTA MULTIFACE E O INCENTIVO À PESQUISA NA GRADUAÇÃO
}

\author{
Josiel Gomes Costa \\ Universidade Federal de Minas Gerais \\ josielgcosta@gmail.com \\ Ivan Prates Sternick \\ Universidade Federal de Minas Gerais \\ ivansternick@gmail.com \\ Ana Carolina Bottega de Lima \\ Universidade Federal de Minas Gerais \\ anabottegalima@gmail.com \\ Claudio Procópio Damasceno Filho \\ Universidade Federal de Minas Gerais \\ cprocopiof@gmail.com \\ Eduardo Pascoal de Freitas \\ Universidade Federal de Minas Gerais \\ eduardopascoalf@gmail.com \\ Giovanni Salvador Santos \\ Universidade Federal de Minas Gerais \\ giovanni.salsantos@gmail.com \\ Vitor Salomão Mourão \\ Universidade Federal de Minas Gerais \\ vitorsalomaomourao@gmail.com
}

\begin{abstract}
Resumo
A Revista Multiface Online é um periódico organizado por alunos de graduação da UFMG e que publica exclusivamente trabalhos produzidos por graduandos, nas áreas de Economia, Administração e Relações Econômicas Internacionais. Contando com dez anos de existência e sendo uma revista disponibilizada no formato digital, a Multiface tem recebido trabalhos de alunos das mais diversas universidades do país. Nesse sentido, este trabalho tem como objetivo apresentar o periódico e as características particulares que o tornam um espaço de incentivo à pesquisa na graduação. Entre estes, está o processo de avaliação, que busca sempre produzir pareceres construtivos, a fim de contribuir para a formação de novos pesquisadores desde a graduação. Além disso, a existência de uma revista editorada por alunos de graduação também possibilita a formação de membros de comitês editoriais desde a graduação.
\end{abstract}

Palavras-chave

Periódico discente. Pesquisa. Publicação.

\section{INTRODUÇÃO}

Com o objetivo de estimular a produção científica no nível de graduação, a Revista Multiface surgiu em 2007, a partir de uma iniciativa de alunos bolsistas do Programa de Educação Tutorial (PET) da Faculdade de Ciências Econômicas (FACE) da Universidade Federal de Minas Gerais (UFMG). Desde a época de publicação da primeira edição, a revista contou com o apoio de diversos órgãos da universidade, tais como o Centro de Desenvolvimento e Planejamento Regional de Minas Gerais (CEDEPLAR) e a Fundação Instituto de Pesquisas Econômicas, Administrativas e Contábeis de Minas Gerais (IPEAD), além da UFMG Consultoria Júnior e do Diretório Acadêmico (DA) da FACE. Esse apoio foi 
primordial para que os nove bolsistas dos cursos de Administração, Ciências Econômicas e Ciências Contábeis executassem as tarefas editoriais e conseguissem viabilizar a audaciosa impressão de 1.000 exemplares logo na primeira edição da revista. Com o objetivo de se tornar referência nacional no que diz respeito a publicações periódicas exclusivas para estudantes de graduação, a Revista Multiface completou dez anos de existência em 2017.

O presente trabalho tem como objetivo apresentar o periódico, descrevendo sua trajetória e destacando as suas características presentes, que o tornam um espaço de incentivo à pesquisa na graduação. $\mathrm{Na}$ seção seguinte, é traçado o histórico e a trajetória da Revista desde sua origem, em 2007. Em seguida, nas seções três e quatro, respectivamente, descrevem-se a estrutura e o modo de funcionamento da revista, que permitem a publicação contínua de qualidade. $\mathrm{Na}$ quinta seção são apresentadas estatísticas e informações relevantes acerca da revista e de suas publicações passadas. Por fim, na sexta e última seção, faz-se uma reflexão sobre os desafios e perspectivas da publicação, tendo em vista seus dez anos e seus objetivos para o futuro.

\section{HISTÓRICO E TRAJETÓRIA DA REVISTA DESDE SUA FUNDAÇÃO}

A Revista Multiface surgiu a partir de uma iniciativa de alunos bolsistas do PET da FACE/UFMG dos cursos de Economia, Administração e Ciências Contábeis, e teve o primeiro volume publicado em abril de 2007. $\mathrm{O}$ interesse em criar a revista, contudo, remete ao final de 2004, como aponta o primeiro Editorial $(2007)^{1}$, período em que se iniciou a árdua e complexa empreitada de tornar realidade um projeto que figurava apenas no campo das ideias. Para tanto, foi necessário um grande esforço por parte dos alunos bolsistas, assim como de apoio e orientação por parte de vários professores e instituições ligadas à UFMG, como o CEDEPLAR, o IPEAD e o DA-FACE.

A inspiração para tal projeto, de acordo com o atual professor do Departamento de Ciências Econômicas da UFMG e membro da primeira comissão editorial da Revista, Ulisses Pereira dos Santos, em relato publicado na seção Relatos sobre a origem e a trajetória da Revista Multiface ${ }^{2}$ (doravante Relatos), foi a descoberta de uma revista que havia circulado na FACE na década de 1950, assim como o lançamento da Revista Três Pontos por alunos do curso de Ciências Sociais da UFMG. No entanto, ainda segundo o mesmo professor, a maior motivação foi a criação de um meio para divulgar as pesquisas elaboradas pelos discentes. Ele afirma:

Muitos trabalhos de boa qualidade eram desenvolvidos no âmbito dos programas de iniciação científica e PET, mas acabavam eternamente engavetados. Não existiam espaços destinados exclusivamente à publicação de trabalhos produzidos por alunos de graduação nas áreas de economia, administração e contabilidade (SANTOS, 2017, p. 4).

A primeira edição da revista, como mencionado, foi publicada em abril de 2007, em formato impresso, com um total de 1000 exemplares, cuja impressão só foi possível graças ao apoio financeiro da Diretoria da FACE e do IPEAD. Os preparativos para a primeira edição, contudo, haviam começado bem antes; em 2005 foi lançada a primeira chamada de artigos, e mais de um ano se passou entre a seleção dos trabalhos, o processo editorial e a resolução dos trâmites burocráticos, ligados especialmente ao financiamento (ibid., p. 4). O primeiro número do primeiro volume continha uma entrevista, sete artigos e uma seção de título "Espaço do DA", que logo se consolidaria como um "espaço de manifestação política

\footnotetext{
${ }^{1}$ Editorial. Revista Multiface, v. 1, n. 1, p. 6-7, 2007.
}

${ }^{2}$ Cf. Relatos sobre a origem e a trajetória da Revista Multiface. Revista Multiface Online, v. 5, n. 2, p. 36, 2017. 
estudantil do Diretório Acadêmico da FACE".

Uma breve análise do primeiro Editorial é reveladora quanto aos ideais que motivaram a criação da Revista, assim como quanto a seus propósitos e ao seu significado para a FACE/UFMG. O intuito fundamental era, de acordo com o primeiro Editorial (2007, p. 6), criar:

"Um espaço para que a graduação da FACE apresente suas ideias e contribuições para a discussão acadêmica, a partir da publicação [...] sendo um fruto da necessidade de materialização do conhecimento transmitido no ambiente acadêmico".

A ambição de criar esse espaço de divulgação e de discussão, ao qual se refere o Editorial, materializou-se com a publicação do primeiro volume, que surgiu, segundo o Editorial (ibid., p. 6): “[...] para apresentar uma nova realidade em meio à graduação [...] a partir do transbordamento do conhecimento e do espírito político que tradicionalmente acompanham a caminhada desta escola". Essa realidade deve apresentar um "caráter multifacetado" (ibid., p. 6), expresso em três pilares, ou eixos orientadores: um eixo acadêmico, cuja pretensão é de fomentar a pesquisa e a produção científica na graduação; um eixo interdisciplinar, que é ao mesmo tempo constituinte da Revista - dado ter ela sido fundada por uma iniciativa de alunos de três cursos distintos - e uma pretensão no sentido de criar "uma ponte [...] visando motivar a integração destas três diferentes ciências [econômicas, administrativas e contábeis]" (ibid., p. 6).

Por fim, o terceiro eixo se refere à face crítica da Revista, que visa manter a publicação como um meio não apenas inserido em um contexto, mas também que busca ter um papel ativo no mesmo, a partir da divulgação do pensamento crítico presente no ambiente universitário. Esse eixo também está intimamente relacionado ao caráter político da Revista, muito presente em seu surgimento, que fez dela "[...] uma espécie de movimento estudantil", que "[...] deve trazer a marca da militância política historicamente enraizada pelos corredores desta faculdade [FACE/UFMG], mas sem se esquecer de seus propósitos acadêmicos" (ibid., p. 7).

Essas foram às ideias que representaram a pedra de toque e todo o ímpeto inicial do projeto. Os pilares fundamentais, concebidos em sua gênese, se mantiveram com o decorrer do tempo, dando-lhe uma coerência e uma identidade. Além disso, pode-se dizer que, com os anos, a Revista cada vez mais se afirmou dentro do ambiente acadêmico, e especialmente do ambiente da FACE, tornando-se mais conhecida pelos discentes e docentes. Ao mesmo tempo, a Multiface muito mudou desde sua primeira edição, seja em escopo, formato e grau de formalização, como será melhor exposto abaixo.

De 2007 a 2011, a revista mantevese no formato impresso e com periodicidade semestral (excetuado o ano de 2009, quando apenas um volume foi publicado). O segundo número de 2007 trouxe uma nova seção para resenhas; o primeiro número de 2008 continha um artigo convidado de título "Treinamento UCJ", que foi o embrião da seção "cases", criada na edição de 2009 , e que se mantém até o presente. No segundo volume de 2011 ocorreram algumas mudanças, como documentado na Carta do Editorial, tais como a introdução de um novo design gráfico, a criação da seção de Textos Introdutórios, e a disponibilização de um portal online inédito, que ainda funciona, no endereço: revistamultiface.wordpress.com, em que se pode consultar as edições impressas em formato digitalizado.

Após essas últimas modificações, a Revista passou por um momento difícil em sua trajetória. Em função do contingenciamento de despesas ocorrido no ano de 2012, o comitê editorial da Revista foi impossibilitado de obter recursos para financiar a impressão dos exemplares do referido ano. Em função disso, não foram publicadas novas edições nesse ano.

No ano seguinte, diante da reiteração do quadro de ausência de financiamento, o comitê editorial optou por uma saída novamente ambiciosa: de transformar a Multiface em uma revista online de acesso 
aberto. Os membros do comitê editorial se empenharam desde 2012 para viabilizar o projeto, que teve seu êxito expresso com a publicação da primeira edição em formato online, o volume 1 do ano de 2013.

Esse evento marcou o renascimento da revista, agora com o nome Revista Multiface Online, e foi uma grande conquista por parte de todos aqueles envolvidos no processo. A revista foi hospedada no sistema Open Journal System (OJS), que é um portal online que abriga um grande número de periódicos científicos, colocando-se em linha com as atualizações feitas no âmbito das principais revistas científicas, no sentido de se tornar online. Como exposto na Carta do Editorial (2013), esse novo formato facilita a organização interna e o acesso ao conteúdo da revista. Além disso, continua o Editorial, o formato exclusivamente online possibilita a ampliação do acesso sem uma ampliação dos custos, sendo uma grande vantagem e uma superação do problema anterior de escassez de recursos. Essa edição manteve continuidade com a estrutura presente nas versões impressas, contendo um case, o "Espaço do DA", dois textos introdutórios e dois artigos.

Os três anos seguintes marcam o período de consolidação da Multiface no sistema OJS e também a busca por maior visibilidade da revista no ambiente acadêmico. Com esse intuito, no ano de 2014, como expresso na Carta do Editorial (2014), a Revista foi incorporada ao Portal de Revistas da FACE e ao catálogo da Rede Pergamum, com o apoio da Biblioteca da FACE. Além disso, o comitê editorial passou a promover eventos semestrais, convidando autores e professores para falar sobre temas relevantes. Esses eventos têm como objetivo oferecer à comunidade acadêmica e externa a oportunidade de debater temas geralmente contidos na edição que está sendo lançada, fomentando o debate entre os participantes. Vale dizer, como lembra o Editorial, que a busca por visibilidade e reconhecimento não foi uma iniciativa exclusiva da Multiface, mas teve (e ainda tem) apoio institucional da FACE e da UFMG.
O apoio mais notável nesse sentido surgiu com a criação da Política de Periódicos da UFMG, por parte da Pró-Reitoria de Pesquisa, lançada oficialmente em 2015. A Multiface foi uma das revistas selecionadas para integrar o então recém-inaugurado Portal de Periódicos da UFMG. Esse portal contempla todos os periódicos da UFMG, discentes e docentes, que se adequam aos critérios exigidos pela Política de Periódicos, tendo dessa forma contribuído muito para aumentar a visibilidade e a maior formalização das revistas da universidade. Além disso, como lembra a Carta do Editorial (2015), a Política de Periódicos da UFMG contempla ainda vários minicursos e oficinas, cujo intuito é fomentar o exercício de editoração e formar editores qualificados.

Os critérios exigidos para entrada e permanência no Portal de Periódicos da UFMG demonstram a preocupação da instituição com a qualidade das revistas publicadas na universidade. Esses critérios, explicitados pelo Comitê Gestor do Portal de Periódicos UFMG (2017), juntamente com outras sugestões para qualidade dos periódicos da UFMG são:

1. Ser editado por membro da UFMG: docente, discente ou técnico. Exceto as situações em que a revista seja interinstitucional, em parceria com a UFMG;

2. Explicitar a tipologia dos artigos publicados, com predominância de artigos inéditos;

3. Ter ISSN eletrônico e deixá-lo explícito na página inicial do site do periódico;

4. Ter acesso aberto e URL ativa;

5. Informar a periodicidade adotada pela publicação;

6. Ter publicado regularmente todos os números relativos aos dois anos anteriores ao ano corrente. Caso a publicação tenha sido criada há menos de dois anos, ter publicado regularmente todos os seus números.

7. Possuir e tornar explícito no site do periódico: foco, escopo, diretrizes para autores e processo de revisão pelos pares (peer review); 
8. Possuir Conselho Editorial com presença de membros de instituições externas à UFMG;

9. Explicitar nome completo e a afiliação de todos os membros do Conselho Editorial no site do periódico;

10. Estar indexado em pelo menos dois indexadores. Os indexadores devem ficar listados no site do periódico;

11. Em cada artigo, explicitar a autoria dos artigos com pelo menos: nome, sobrenome, contato e afiliação do(s) autor(es);

12. Informar as normas de publicação adotadas (nacionais ou internacionais) nas diretrizes para autores;

13. Explicitar no site o e-mail principal de contato do periódico.

Uma iniciativa que tem a mesma direção é o lançamento do Portal Periódicos de Minas, vinculado à Fundação de Amparo à Pesquisa do Estado de Minas Gerais (FAPEMIG), ao qual a Multiface também está integrada. Este portal contém mais de 400 periódicos do estado e emerge como importante instrumento de visibilidade e, espera-se, apoio para a Multiface nos próximos anos.

Desde sua retomada em 2013, a revista se manteve em publicação anual. No entanto, com o aumento do número de submissões, julgou-se conveniente voltar, em 2016, para a publicação de periodicidade semestral. Esse retorno foi feito de modo a corrigir uma aparente defasagem nas publicações, que havia se originado devido ao período de inatividade da revista, com a publicação de um dos números de 2016 sob a data de 2015 (v. 3, 2015), e o segundo número como o volume 4 de 2016. Nesse sentido, 2017 foi o ano em que a periodicidade semestral foi consolidada, com o lançamento de dois números do volume 5 , publicados em junho e novembro.

A transição para a plataforma online também possibilitou o aumento da visibilidade da revista. No ano de 2017, a Multiface foi indexada a quatro grandes bases bibliográficas, a saber, o Sistema Regional de
Información en Línea para Revistas Científicas de América Latina, el Caribe, España y Portugal (Latindex), Directory of Open Access Journals (DOAJ), Scientific Indexing Services (SIS) e Google Scholar. Esse passo foi feito em conformidade com um dos critérios exigidos para permanência no Portal de Periódicos da UFMG, e foi importante para aumentar a formalização da Revista.

Ainda nessa linha, o corpo de avaliadores passou por um processo de atualização e expansão. Como registra a Carta do Editorial (2017b), foi realizada uma chamada de novos avaliadores em âmbito nacional, que possibilitou incluir pareceristas qualificados de universidades renomadas do Brasil, como a Universidade Federal do Rio de Janeiro (UFRJ), a Universidade Federal do Ceará (UFC) e a Fundação Getúlio Vargas (FGV).

Sob essas considerações, registra-se que 2017 marcou o aniversário de dez anos da publicação da primeira edição, coincidindo com o lançamento do quinto volume da versão online. A revista recebeu apoio financeiro da Pró-Reitoria de Assuntos Estudantis (PRAE/UFMG) para realização do projeto de comemoração dos seus dez anos; com o suporte financeiro da PRAE, e o apoio institucional da FACE e da Política de Periódicos, o comitê editorial organizou dois eventos no ano de 2017, um em junho e o outro em novembro. No primeiro, foram convidados alguns daqueles que estiveram presentes na concepção e na fundação propriamente dita da revista, além de outras figuras importantes relacionadas ao apoio institucional, para trazerem seus relatos. No segundo evento, promoveu-se uma mesa redonda para discutir a importância da experiência da publicação na graduação. Tudo isso levou o ex-membro do comitê editorial, e atual professor da FACE, Ulisses Pereira dos Santos, a afirmar em seu relato dado à revista:

Hoje, como docente da FACE, posso testemunhar que nossa revista é muito maior do que aquilo que imaginávamos que um dia seria. A Multiface extrapola os limites da faculdade em que nasceu, abrindo espaço para a divulgação de 
trabalhos acadêmicos de estudantes de graduação de todo o país. A revista mudou, se modernizou, adotou um novo modelo editorial, ampliou seu escopo, criou novos canais de divulgação e se tornou reconhecida (SANTOS, 2017, p. 5).

As várias alterações mencionadas pelas quais passou a Multiface conferiram à revista, em seu aniversário de dez anos, uma nova "feição", por assim dizer. No entanto, o "novo" não ofuscou o "velho", e embora as novas circunstâncias da atualidade criem novos desafios e necessidades, a Revista ainda carrega com vigor os eixos que nortearam e inspiraram sua concepção. Nesse sentido, vale dizer, as atualizações e alterações feitas (e por fazer) no sentido de aumentar a formalização da Multiface, e colocá-la em linha com os principais periódicos, não vieram desprovidas de crítica e ponderação; buscou-se (e busca-se) conciliar as necessidades colocadas pelo presente com os valores originários e com aquele "espírito", referido do primeiro editorial, que é tão característico da revista e da FACE/UFMG.

\section{A ESTRUTURA DA REVISTA}

Após o lançamento de nove edições, os sucessivos contingenciamentos de recursos fizeram com que os principais financiadores da revista em formato impresso retirassem a quantia que era repassada à Multiface. Por conta disso, a revista ficou sem publicação por dois anos, sendo retomada em 2014, novamente pelos bolsistas, mas dessa vez com o nome de Revista Multiface Online, disponível apenas no formato virtual, como o novo nome sugere. A revista está hospedada no endereço eletrônico: revistas.face.ufmg.br/multiface, e utiliza a plataforma OJS, também conhecida no Brasil como Sistema Eletrônico de Editoração de Revistas (SEER), para gerenciamento e suporte à publicação online. A quase totalidade dos principais periódicos científicos da área utiliza a mesma plataforma.

A revista continua recebendo exclusivamente trabalhos de alunos de graduação, nas áreas de Administração, Economia e Relações Econômicas
Internacionais. Além de artigos, são publicadas resenhas, cases e textos introdutórios nessas áreas. Os artigos submetidos devem ser inéditos e resultantes de pesquisa científica original ou de trabalhos feitos para conclusão de curso. Além de artigos das áreas já citadas anteriormente, há uma seção para publicação de artigos livres, que são aqueles que não se enquadram nessas áreas.

As resenhas publicadas possuem o objetivo de apresentar um livro, fornecendo uma ideia do assunto principal da obra e uma análise crítica a partir de outras referências. Os textos introdutórios, por sua vez, objetivam introduzir um tema ou debate relevante nas áreas de Economia ou Administração, de forma menos densa. Essa seção é voltada para os autores que estão começando sua trajetória acadêmica e permite o contato com a publicação sem a complexidade de um artigo. Os textos introdutórios em geral apresentam novas áreas de pesquisa e podem guiar a elaboração de um trabalho futuro.

Os cases publicados são estudos de caso a respeito de uma empresa, de um projeto ou mesmo de um grupo, mostrando a aplicação prática de teorias ensinadas na sala de aula. Além disso, a revista conta com uma seção de entrevistas (relatos de profissionais que possam contribuir para uma nova visão dos graduandos sobre as suas áreas de atuação), bem como um espaço do DA, no qual é apresentada uma análise de uma questão que influencia a comunidade universitária, sob a perspectiva desse importante órgão de mobilização estudantil.

\section{O PROCESSO EDITORIAL}

Acumulando as tarefas editoriais de divulgação, de diagramação, de orçamento e todas as demais tarefas necessárias à publicação da revista, atualmente o comitê editorial da revista Multiface é composto por representantes dos PETs dos cursos de Administração e Ciências Econômicas e por bolsistas do Sistema de Bolsas do curso de Relações Econômicas Internacionais, todos da UFMG. Sendo diretamente responsáveis 
pelo desenvolvimento da revista, os membros do comitê editorial são alterados quando deixam de fazer parte dos programas citados.

O processo de avaliação dos artigos é executado no sistema blind review, sendo entregues a pareceristas anônimos do conselho editorial ou para especialistas ad hoc anônimos para apreciação e emissão de parecer. O fluxo do processo de avaliação segue o processo utilizado nos principais periódicos científicos e está resumido na Figura 1.

No fluxograma é possível notar que as resenhas, cases e textos introdutórios são avaliados pelo próprio comitê editorial. Os membros do comitê editorial avaliam as resenhas no que tange à capacidade do texto de difundir o conhecimento da obra no debate acadêmico e cultural, enquanto os textos introdutórios são avaliados pela clareza de exposição do tema, verificando também se há apoio adequado na literatura consolidada da área. No que concerne aos cases, sua avaliação tem em vista a relevância do projeto apresentado, assim como das alternativas de solução ou condução do projeto apresentadas.

Os artigos, da área livre ou não, por sua vez, são apreciados, em termos gerais, nos seguintes pontos: originalidade, atualidade e relevância do artigo; articulação de ideias e qualidade de escrita; e adequação às normas de publicação da revista. Também vale ressaltar que os pareceristas são instruídos a fornecer avaliações construtivas para a formação do aluno, identificando os pontos fortes dos trabalhos e recomendando novas leituras que possam ajudar a melhorá-lo. 
Josiel Gomes Costa, Ivan Prates Sternick, Ana Carolina Bottega de Lima, Claudio Procópio Damasceno Filho, Eduardo Pascoal de Freitas, Giovanni Salvador Santos, Vitor Salomão Mourão

Figura 1. Fluxograma do processo de avaliação dos trabalhos submetidos à revista

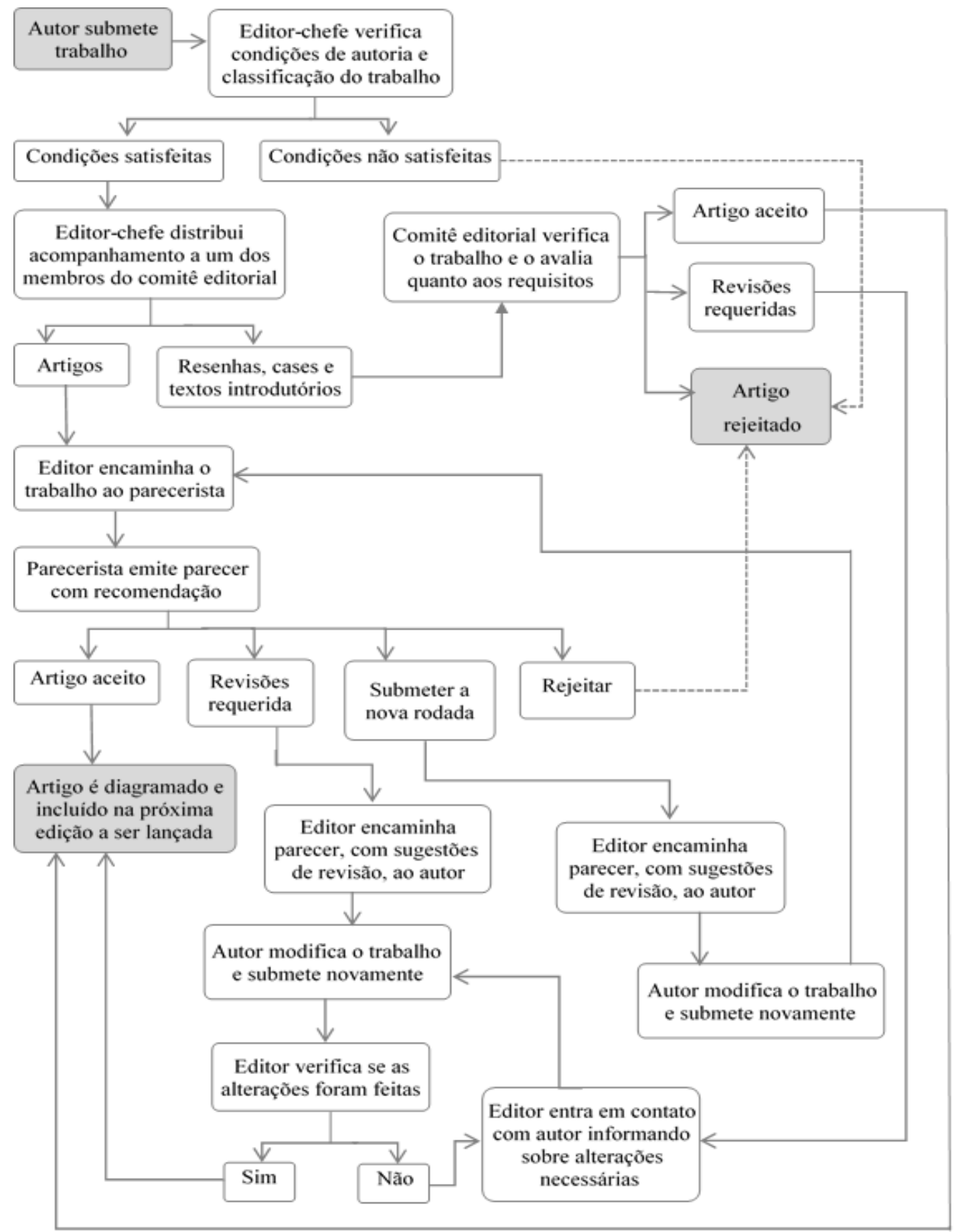

Fonte: elaborado pelos autores (2017)

\section{ESTATÍSTICAS E INFORMAÇÕES}

Com relação ao acesso, a revista está vinculada Portal de Revistas da FACE e ao catálogo da Rede Pergamum. A Multiface também foi incorporada ao Portal de Periódicos da UFMG em 2015 e, mais recentemente, ao Portal Periódicos de Minas, que é uma iniciativa da FAPEMIG para disponibilizar acesso a quase 400 revistas científicas sediadas no Estado. Além disso, como mencionado, ela se encontra indexada em quatro grandes bases bibliográficas: Latindex, DOAJ, SIS e Google Scholar.

O periódico demonstra já ganhar capilaridade no que diz respeito a outras 
universidades do Brasil, e se espera alcançar outras universidades pelo mundo. Desde a primeira edição, a revista Multiface tem recebido trabalhos de universidades como Universidade de São Paulo (USP), Pontifícia Universidade Católica do Rio de Janeiro (PUC-Rio), Pontifícia Universidade Católica de São Paulo (PUC-SP), Universidade Federal do Maranhão (UFMA), Universidade Federal de Ouro Preto (UFOP), Universidade Federal do Paraná (UFPR),
Universidade Federal do Rio Grande do Sul (UFRGS), Universidade Federal de Uberlândia (UFU) e Universidade Federal do Ceará (UFC), além de ter recebido uma submissão do Instituto Superior Politécnico de Viana do Castelo, de Portugal. Além disso, o número de submissões anuais e a quantidade de usuários cadastrados no site da revista cresceram desde a implantação do formato online, conforme se verifica no Gráfico 1 abaixo:

Gráfico 1. Total de submissões recebidas por ano e total de usuários cadastrados no site da revista por ano

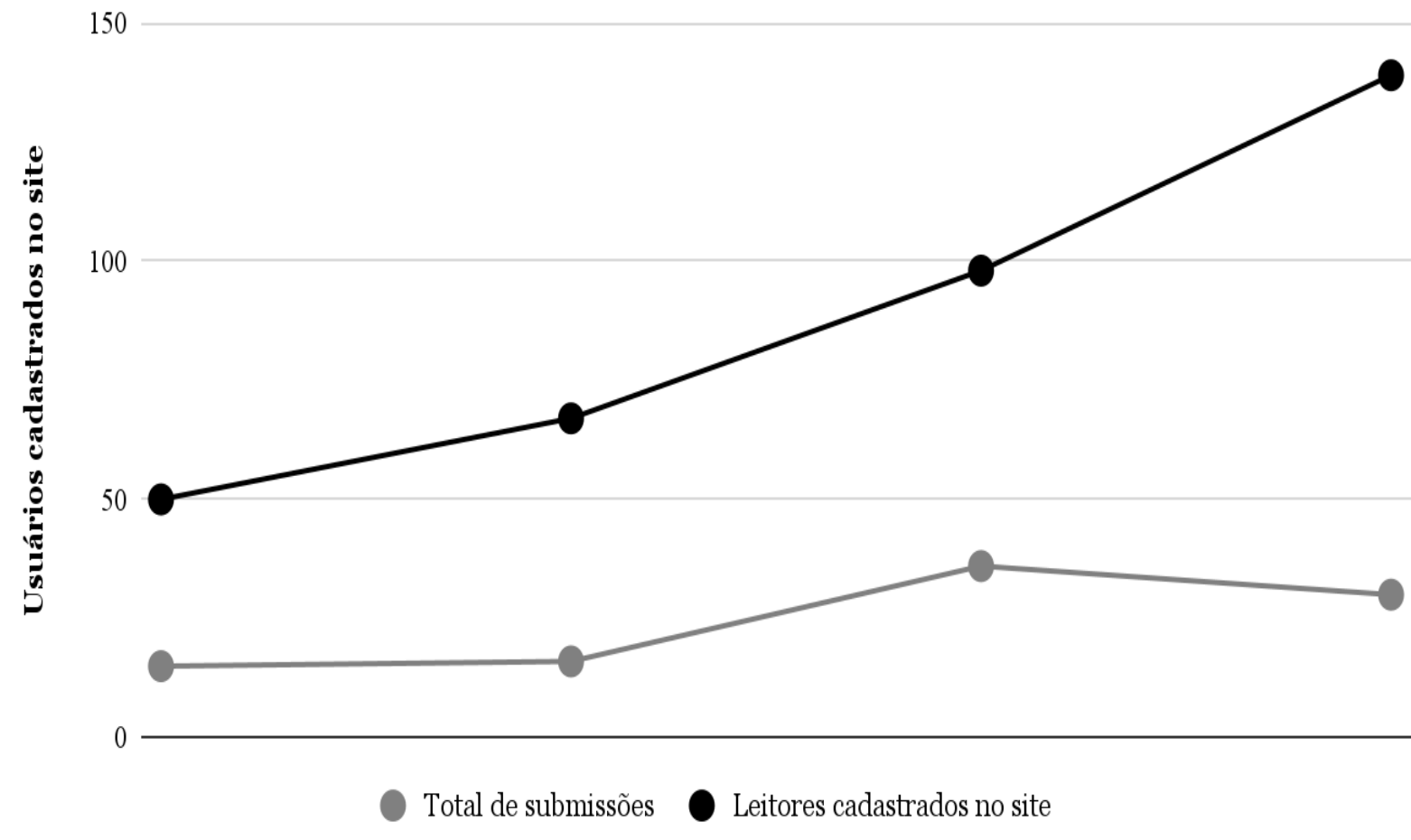

Fonte: elaborado pelos autores (2017)

Relatórios retirados do sistema OJS apontam um tempo médio de avaliação de 27,41 dias entre a submissão e a conclusão de uma etapa de avaliação (seja a aceitação do artigo ou emissão do parecer pelo membro do conselho editorial). Os textos mais acessados na versão online da revista são da área de Economia, conforme é possível verificar no Gráfico 2: 
Gráfico 2. Textos mais acessados na versão online da revista Multiface

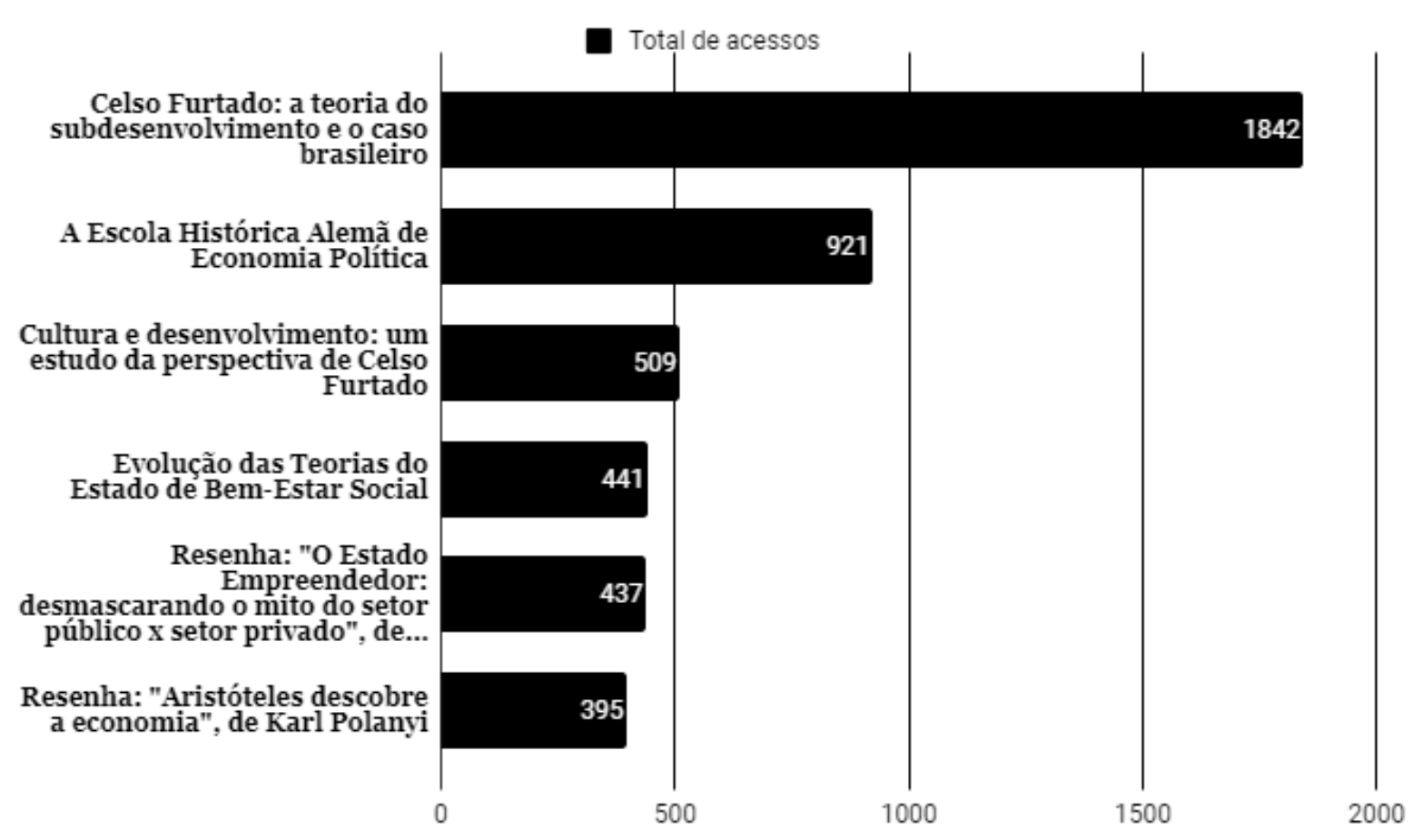

Fonte: elaborado pelos autores (2017)

\section{DESAFIOS E PERSPECTIVAS}

O contingenciamento de recursos pelo qual tem passado a universidade pública se reflete também na área de divulgação da produção acadêmica e constitui um desafio para a publicação científica. Além da impossibilidade de existir uma versão impressa da revista, as limitações orçamentárias impostas à revista Multiface obrigam os membros do comitê editorial a utilizar ferramentas de detecção de plágio e diagramação gratuitas (as quais, apesar de servirem ao propósito principal, não oferecem as mesmas possibilidades de seus equivalentes pagos). Ademais, $\mathrm{O}$ armazenamento dos arquivos com as versões finais de todas as edições da revista é feito em servidores web que possuem limites de espaço que em breve serão atingidos.

Por outro lado, a oportunidade de participar de uma publicação científica durante a graduação se coloca como um importante meio de formação dos membros do comitê editorial. Isso porque a tarefa de organizar e coordenar um periódico em geral não faz parte dos currículos de graduação ou mesmo pós-graduação, e não é estimulada antes de se assumir esse tipo de tarefa. Como um periódico discente, a revista Multiface favorece este tipo de capacitação.

Conforme foi exposto neste trabalho, a revista Multiface se propõe a ser, primordialmente, um espaço interdisciplinar para incentivo à pesquisa na graduação e para a divulgação do pensamento crítico acadêmico. Ao possibilitar aos discentes o contato com uma crítica construtiva de seu trabalho, representa uma ação de estímulo à produção científica, bem como estimula a formação de futuros pesquisadores, os quais possuirão visão crítica diante do próprio trabalho e estarão dispostos a aprimorá-lo a partir de comentários de seus pares. Ao longo dos seus dez anos, a revista cumpriu com sucesso esse propósito, e para os próximos anos, continua comprometida com a divulgação científica de qualidade advinda dos graduandos. 


\title{
TEN YEARS OF REVISTA MULTIFACE AND THE INCENTIVE OF RESEARCH IN UNDERGRADUATE COURSES
}

\begin{abstract}
Revista Multiface Online is a journal organized by undergraduate students of UFMG and publishes exclusively works produced by undergraduates in the areas of Economics, Administration and International Economic Relations. With 10 years of existence and being a magazine available in digital format, Multiface has received works from students of several universities of Brazil. In this regard, this paper aims to present the journal and the particular characteristics that make it an incentive space of research in undergraduate level. Among these is the evaluation process, which always seeks to produce constructive opinions, in order to contribute to the shaping of new researchers since undergraduate courses. In addition to that, the existence of a journal published by undergraduate students also allows the shaping of members of editorial committees since this level of education.
\end{abstract}

\section{Keywords}

Undergraduate journal. Research. Publication. Artigo recebido em 14/01/2018 e aceito para publicação em 16/02/2018

\section{REFERÊNCIAS}

BRASIL. Universidade Federal de Minas Gerais. Faculdade de Ciências Econômicas. Carta do Editorial. Carta do Editorial: Revista Multiface, Belo Horizonte, v. 1, n. 1, p. 6-7, 2007.

Universidade Federal de Minas Gerais. Faculdade de Ciências Econômicas. Carta do Editorial. Carta do Editorial: Revista Multiface, Belo Horizonte, v. 5, n. 1, p. 6-7, 2011.

- Universidade Federal de Minas Gerais. Faculdade de Ciências Econômicas. Carta do Editorial. Carta do Editorial: Revista Multiface Online, Belo Horizonte, v. 1, p. 2, 2013. Anual. Disponível em: < http://revistas.face.ufmg.br/index.php/mul tiface/article/view/2621/1421>. Acesso em: 28 nov. 2017.

Universidade Federal de Minas Gerais. Faculdade de Ciências Econômicas. Carta do Editorial. Carta do Editorial: Revista Multiface Online, Belo Horizonte, v. 2, p. 3, 2014. Anual. Disponível em: < http://revistas.face.ufmg.br/index.php/mul tiface/article/view/3085>. Acesso em: 10 dez.2017.
Universidade Federal de Minas

Gerais. Faculdade de Ciências Econômicas. Carta do Editorial. Carta do Editorial: Revista Multiface Online, Belo Horizonte, v. 3, p. 3, 2015. Anual. Disponível em: < http://revistas.face.ufmg.br/index.php/mul tiface/article/view/3506/1746>. Acesso em10 dez. 2017.

a. Universidade Federal de Minas Gerais. Faculdade de Ciências Econômicas. Carta do Editorial. Carta do Editorial: Revista Multiface Online, Belo Horizonte, v. 5, n. 1, p. 2, 2017. Semestral. Disponível em: $<$

http://revistas.face.ufmg.br/index.php/mul tiface/article/view/4174/1929>. Acesso em: 28 nov. 2017.

b. Universidade Federal de Minas Gerais. Faculdade de Ciências Econômicas. Carta do Editorial. Carta do Editorial: Revista Multiface Online, Belo Horizonte, v. 5, n. 2, p.2-3, 2017. Semestral. Disponível em: $<$

http://revistas.face.ufmg.br/index.php/mul tiface/article/view/4520/2052>. Acesso em: 10 dez. 2017.

COMITÊ GESTOR DO PORTAL DE PERIÓDICOS UFMG. Critérios para entrada e permanência no Portal de Periódicos UFMG: 2017. Belo Horizonte: Biblioteca Central UFMG, 2017. 
SANTOS, Ulisses Pereira dos. Relatos sobre a origem e a trajetória da revista multiface. Disponivel em:

$<\underline{\text { http://revistas.face.ufmg.br/index.php } / \mathrm{m}}$ ultiface/>. Acesso em: 10. Dez. 2017

i Versão revista e ampliada do Trabalho "10 anos da Revista Multiface e o incentivo à pesquisa na graduação" apresentado no evento ABEC MEETING, 6-9, novembro, Curitiba, PR, 2017 